\title{
A Case of Mania following Deep Brain Stimulation for Obsessive Compulsive Disorder
}

\author{
Ihtsham U. Haq ${ }^{a}$ Kelly D. Foote ${ }^{c}$ Wayne K. Goodman ${ }^{\text {b, d }}$ Nicola Ricciuti $^{d}$ \\ Herbert Ward $^{d}$ Atchar Sudhyadhom $^{e}$ Charles E. Jacobson $^{f}$ \\ Mustafa S. Siddiqui ${ }^{a}$ Michael S. Okun ${ }^{c, d, f}$ \\ a Department of Neurology, Wake Forest University Health Sciences, Winston-Salem, N.C., b Department of \\ Psychiatry, Mount Sinai Medical Center, New York, N.Y., and Departments of ${ }^{\mathrm{C} N e u r o s u r g e r y, ~}{ }^{\mathrm{d}}$ Psychiatry, \\ eNuclear and Radiological Sciences and f Neurology, McKnight Brain Institute, University of Florida, \\ Gainesville, Fla., USA
}

\section{Key Words}

Obsessive compulsive disorder - Deep brain stimulation, side effects $\cdot$ Neuropsychiatric mania

\begin{abstract}
Deep brain stimulation (DBS) of the basal ganglia is an effective treatment for select movement disorders, including Parkinson's disease, essential tremor and dystonia. Based on these successes, DBS has been explored as an experimental treatment for medication-resistant neuropsychiatric disease. During a multiyear experience employing DBS to treat patients for obsessive compulsive disorder (OCD) we encountered several unanticipated stimulation-induced psychiatric side effects. We present a case of a young woman treated for OCD with DBS of the anterior limb of the internal capsule and nucleus accumbens region, who subsequently manifested a manic episode. We aim to discuss the case details, treatment and potential neuroanatomical underpinnings of this response.

Copyright $\odot 2010$ S. Karger AG, Basel
\end{abstract}

\section{Introduction}

Deep brain stimulation (DBS) of the basal ganglia is an effective treatment for movement disorders such as Parkinson's disease, essential tremor and dystonia [1-8]. Based on these initial successes, DBS has been explored as an experimental treatment for select medication-refractory neuropsychiatric diseases, including obsessive compulsive disorder (OCD) [9-13]. The published experience with DBS programming for OCD is limited [10, 12-15]. Parameters (voltage, pulse width and frequency) are commonly adjusted by trial and error with the aim of deriving the greatest possible clinical efficacy while avoiding uncomfortable side effects. As physicians' experience with DBS programming in OCD has broadened, the potential for stimulation-induced side effects has become increasingly apparent. Novel targets, such as the anterior limb of the internal capsule/nucleus accumbens (ALIC-NA), have introduced novel stimulation-induced effects [12].

\section{KARGER}

๑ 2010 S. Karger AG, Basel

Fax +41613061234 E-Mail karger@karger.ch www.karger.com 
Fig. 1. Lead trajectory and contact coordinates for patient 6 based on postoperative CT to preoperative $T_{1}$-weighted MRI fusion in right coronal (A), left coronal (B), right sagittal (C) and left sagittal (D) views. We employed a 3387-IES Medtronics DBS lead (3-mm-long contacts, 4-mm spacing). The tip of the electrode was targeted to pass along the ALIC and approximately through the anterior commissure with the ventral extent to be placed within the NA. The target coordinates were $(\mathrm{x}, \mathrm{y}, \mathrm{z})=$ $( \pm /-6.0,12.5,-5.0)$, where $\mathrm{x}=$ lateral, $\mathrm{y}=$ anteroposterior and $\mathrm{z}=$ axial. Adapted from Haq et al. [31].

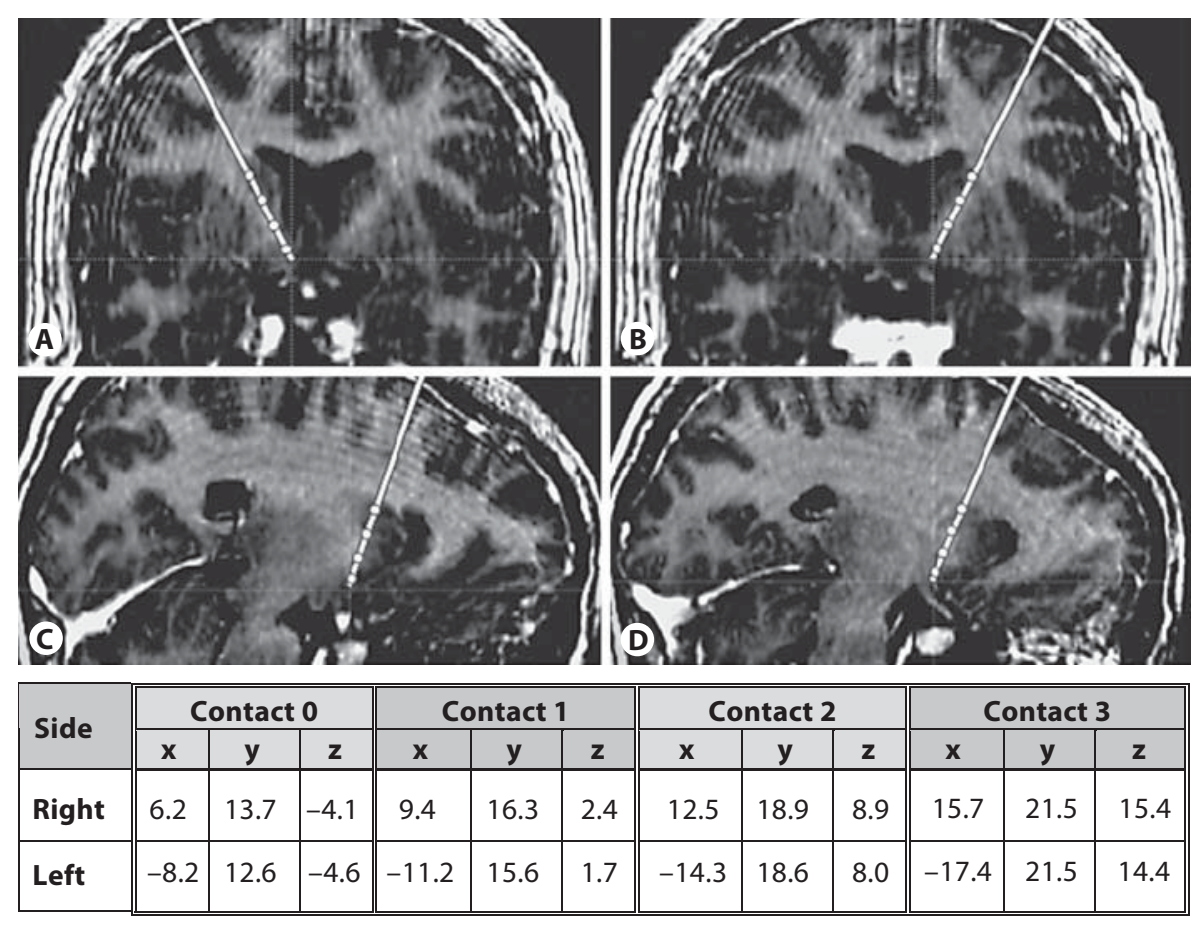

We recently implanted DBS leads in 6 patients to treat medication-resistant OCD. The tip of the DBS lead was targeted to pass along the ALIC and through the anterior commissure. The ventral extent of the lead was targeted to the NA. A single track of microelectrode recording was performed before the final lead implantation during which we sometimes encountered striatum and accumbens. We relied primarily on the MRI for final lead location (fig. 1). Microelectrode recording/implantation was first performed on the right side of the brain, followed by the left. The patients were randomized to either have their device turned on 30 days after surgery or to receive sham stimulation for 1 month (i.e. turned on on day 60 after surgery) [13].

During programming, optimization of the device settings sometimes resulted in neuropsychiatric manifestations such as euphoria, smiling, laughter and panic [12]. In most patients these manifestations were brief (lasting $1.5 \mathrm{~min}$ or less) and were most consistently encountered intraoperatively or immediately postoperatively [16]. We report here a postprogramming episode of mania in a single patient. This episode required several days of inpatient hospitalization for management and stabilization.

Though manic episodes have previously been described following both subthalamic nucleus (STN) [17-
18] and globus pallidus [19] DBS, there are no detailed case reports of mania following ALIC-NA DBS. In this paper we will discuss our treatment of this manic episode, its possible neuroanatomical underpinnings and the implications that these types of side effect may present for future applications of DBS technology.

\section{Case Details}

The study was approved by the institutional review board and the patients gave written informed consent before entering. To be eligible, the patients were required to have undergone adequate therapeutic trials of at least 3 classes of medication and also to have received multiple trials of cognitive behavioral therapy without benefit.

A 29-year-old woman with a history of severe OCD enrolled in the study. She reported that her OCD symptoms had manifested themselves at the age of 5 with obsessions that centered on a need to be clean and a need to please. At the time of enrollment, her compulsions included counting, bra-snapping, pant-pulling and leg scratching. She completed the 12 th grade but subsequently had difficulty remaining employed because of her illness. In addition to her history of OCD, she was also diagnosed as having major depressive disorder. Twice, in the remote past, she had attempted suicide via drug overdose. The patient underwent DBS and pulse generator implantation without ill effects. Details of the neurosurgical procedure have been previously published [12]. She had been randomized to the 'activation at 30 days postoperative- 
Table 1. Programming settings and patient behaviors

\begin{tabular}{|c|c|c|c|c|c|c|c|c|c|c|}
\hline \multirow{2}{*}{$\begin{array}{l}\text { Days after } \\
\text { activation }\end{array}$} & \multirow{2}{*}{ Time } & \multicolumn{4}{|l|}{ Right } & \multicolumn{4}{|l|}{ Left } & \multirow[t]{2}{*}{ Behavioral changes } \\
\hline & & settings & voltage & freq. & PW & settings & voltage & freq. & PW & \\
\hline Day 0 & $\mathrm{AM}$ & $1-\mathrm{C}+$ & 4.8 & 135 & 210 & $1-\mathrm{C}+$ & 4.8 & 135 & 210 & excessively friendly (hugging), pressured speech \\
\hline Day 0 & $\mathrm{PM}$ & $1-\mathrm{C}+$ & 3.0 & 135 & 210 & $1-\mathrm{C}+$ & 3.0 & 135 & 210 & $\begin{array}{l}\text { OCD symptoms reportedly worse, continuous, } \\
\text { insomnia second to task-directed behavior }\end{array}$ \\
\hline Day 1 & $\mathrm{AM}$ & $0-1-\mathrm{C}+$ & 2.5 & 135 & 210 & $0-1-\mathrm{C}+$ & 2.5 & 135 & 210 & $\begin{array}{l}\text { somewhat sleepy; mania resolved; OCD symptoms } \\
\text { persist; admitted to inpatient psychiatry }\end{array}$ \\
\hline Day 2 & $\mathrm{AM}$ & $0-\mathrm{C}+$ & 3.0 & 135 & 210 & $0-\mathrm{C}+$ & 3.0 & 135 & 210 & sleepy, but appropriate when aroused \\
\hline Day 3 & $\mathrm{AM}$ & $1-0+$ & 2.5 & 135 & 90 & $1-0+$ & 2.5 & 135 & 90 & OCD symptoms improved \\
\hline Day 6 & $\mathrm{AM}$ & $1-0+$ & 3.0 & 135 & 90 & $1-0+$ & 3.0 & 135 & 90 & $\begin{array}{l}\text { troubled by rituals to relieve effects of 'negative } \\
\text { appearance' of others }\end{array}$ \\
\hline Day 7 & $\mathrm{AM}$ & $1-0+$ & 3.3 & 135 & 90 & $1-0+$ & 3.3 & 135 & 90 & $\begin{array}{l}\text { OCD symptoms improved, now waxing and waning; } \\
\text { child-like affect }\end{array}$ \\
\hline Day 8 & $\mathrm{AM}$ & $1-0+$ & 3.5 & 135 & 90 & $1-0+$ & 3.5 & 135 & 90 & $\begin{array}{l}\text { OCD symptoms remain improved; discharged to } \\
\text { care of aunt }\end{array}$ \\
\hline
\end{tabular}

Statements in quotes are from the patient's diary, which was submitted by her and entered into the medical record. Medication changes included reduction in her fluoxetine dosage and discontinuation of topiramate on day 0 , and the addition of quetiapine (100 mg q.h.s. from day 3) and clonazepam (2 mg b.i.d. from day 3). PW = Pulse width.

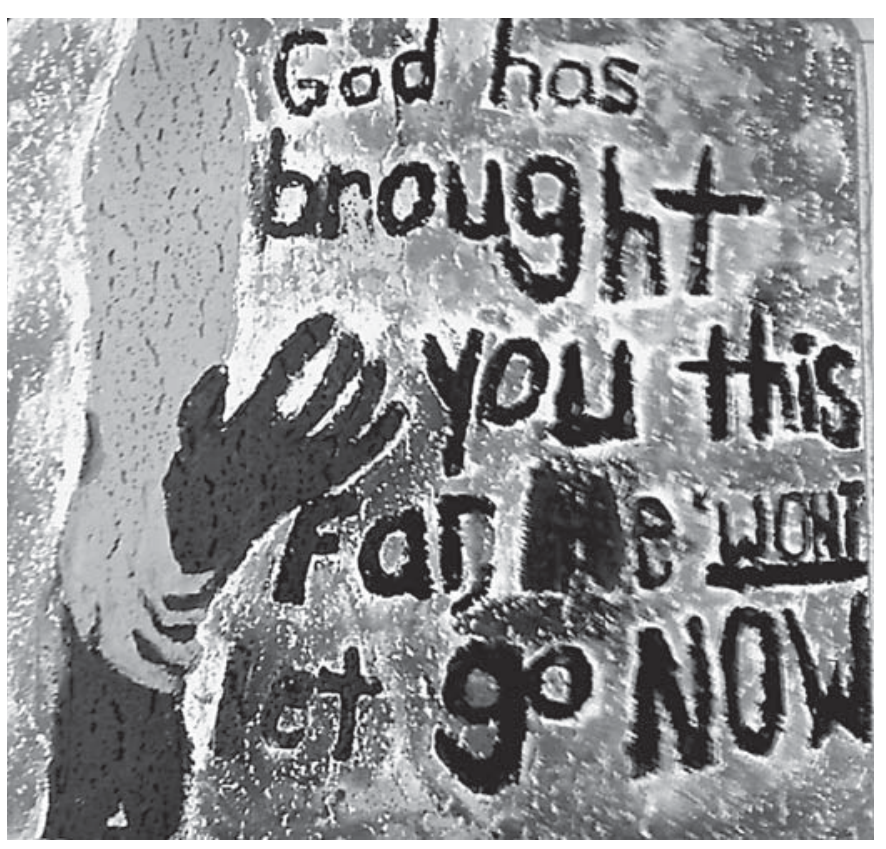

Fig. 2. A painting made following initial ALIC-NA DBS activation. It was produced after a night-long effort and was described as a 'surprise' for the staff. The religious tone is typical of the patient. ly' group, and 1 month after implantation her generators were turned on.

Following a detailed screening procedure, in which we assessed patient response to stimulation settings in a blinded manner [12], the subject was set to what were felt to be the clinically optimal contact and parameter settings (table 1). Though electrode placement within the ALIC-NA was chosen in order to facilitate stimulation at either the ALIC or NA, our experience with the previous 5 patients in this trial [12], as well as the experience of other centers [20], led us to attempt stimulation of the NA first. Within $30 \mathrm{~min}$ after device activation, the patient's speech became rapid and pressured. Our initial concern was lead misplacement or migration. A CT scan of her head confirmed accurate lead position without intracranial hemorrhage or lead migration. During this procedure the patient continued to be unusually ebullient and talkative. She repeatedly interrupted the scan in order to express her gratitude, rising from the scanner several times in order to thank and hug the staff. She was noticed to be unusually upbeat and voluble. This behavior was in marked contrast to her usually restricted affect and quiet demeanor. She was subsequently admitted to the psychiatric ward for inpatient observation.

Her medication regimen at the time of admission consisted of fluoxetine (100 mg daily), lamotrigine (200 mg q.h.s.), eszopiclone (3 mg q.h.s.), pregabaline (50 mg b.i.d.), clonazepam (1 mg daily) and topiramate (25 mg q.h.s.). Her DBS programming parameters at this time were (bilaterally) $1-\mathrm{C}+$ with a PW of $210 \mu \mathrm{s}$, frequency of $135 \mathrm{~Hz}$ and voltage of stimulation of 4.8 . 
Fig. 3. Stimulation intensity is shown in terms of TED calculated according to the equation TED $=\mathrm{V}^{2} \times \mathrm{PW} \times \mathrm{f} / \mathrm{I}$, where $\mathrm{V}=$ voltage, $\mathrm{PW}=$ pulse width, $\mathrm{f}=$ frequency and $\mathrm{I}=$ impedance. After the rapid reduction in TED of the first day her symptoms of mania resolved. The patient's OCD symptoms began to improve from day 3 of stimulation onwards. On day 0 four medication changes were made: the patient's fluoxetine dose was decreased, her topiramate was discontinued, and treatments with nightly doses of $100 \mathrm{mg}$ of quetiapine and $2 \mathrm{mg}$ of clonazepam were concurrently initiated. No further medication changes were made after day 0 .

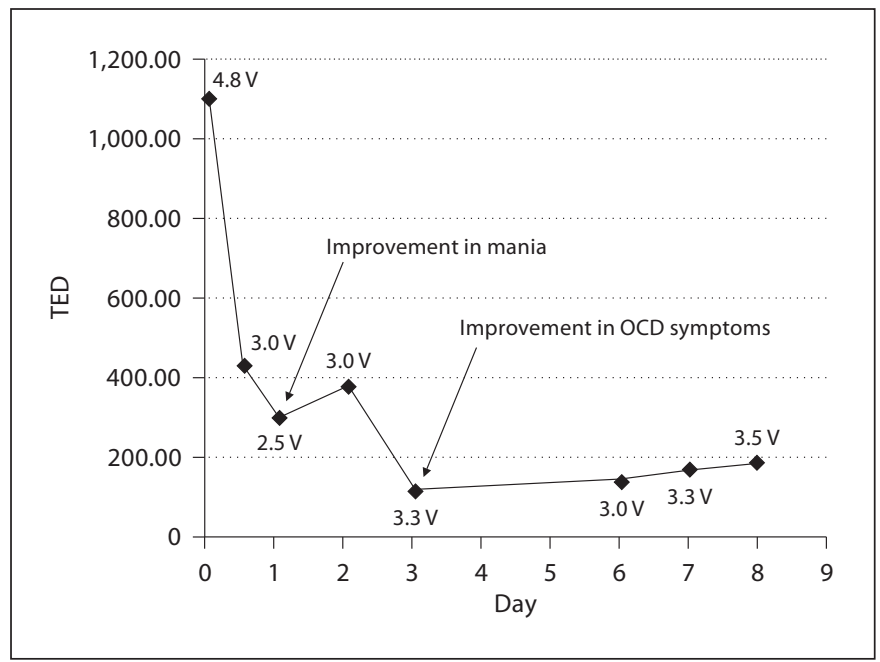

\section{Discussion}

Transient mania has been reported following successful DBS implantations in several basal ganglion targets. These have included the globus pallidus internus [19], the STN [17-18, 21-22], the substantia nigra [23] and now the ALIC-NA region [10]. In our patient, the treatment plan involved both a reduction in stimulation field density (via a change in active contact and a change to a bipolar setting which has a smaller and focused stimulation field) and multiple medication changes. The ultimate outcome was positive - her mania resolved and her OCD responded to DBS parameter changes. Multiple modalities were employed to stabilize her clinical course and it is difficult to ascertain the weighted relevance of each. We suspect, based on the time course of improvement, that stimulation played the largest role.

Stimulation-induced mania may result from spread of the stimulation field from the motor regions of gray matter structures into limbic or frontal territories, as has been observed commonly in STN DBS for Parkinson's disease [24-25]. The ALIC-NA is more richly connected to limbic and frontal regions [26] than the STN or other basal ganglion targets and (based on limited experience) has a correspondingly higher incidence of postoperative psychiatric side effects $[10,12]$. The occurrence of transient hypomania with ALIC-NA DBS has been estimated to be as high as $50-67 \%[10,12]$, as contrasted with $4-8 \%$ in STN DBS patients [27]. Ventral and anterior stimulation in the ALIC-NA region may produce psychiatric side effects more frequently $[10,12]$. It should be noted 
that the NA has been implicated in the processing of both executive function and reward-seeking behavior [28-30] mediated via striatal-orbitofrontal circuits. Manic behavior consists in part of impairment in these domains, with patients displaying exaggerated reward-seeking behaviors and overoptimistically assessing the outcomes of their actions. It is unclear what relative roles the NA, striatum and orbitofrontal cortex (OFC) might play in mania: stimulation at the NA has been observed to produce euphoria [31], the striatum has been tied to the experience of pleasure [29] and fMRI data suggest that OFC abnormalities can be present in patients with mania during expected-gain tasks [32]. There is some evidence that ALIC-NA DBS modulates these circuits: high-frequency stimulation of the NA has been shown to inhibit the firing of OFC neurons in rats [33] and intraoperative ventral ALIC-NA stimulation has been found to acutely elevate mood [31]. We hypothesize that the effects we observed occurred either due to stimulation-related impairment of NA-OFC connections or due to activation of related areas in the ALIC-NA itself, but these relationships will require considerable and detailed study to elucidate.

Though the degree of stimulation spread is partially dictated by lead placement - which sets the center of the stimulation field - the shape and intensity of the electrical field also play a role in determining potential side effects/ benefits. One reason for mania in our case may have been the high initial stimulation intensity. Aggregate stimulation intensity can be approximated by utilizing the composite measure referred to as total energy delivered (TED) [34]. When examining TED over time (fig. 3), calculations revealed maximal intensity at activation (TED = $1,098.27$ ) with a reduction over the time course of OCD improvement $($ TED $=188.67$ at discharge and TED $=$ 194.98 one year postoperatively). It should be noted that even minor variation in lead activations or configurations can result in large changes in the region influenced by the stimulation field [35]. We employed a Medtronics $3387-I E S$ lead and a shift from the 0 (or ventral) contact to contact 1 corresponded to a shift of $4 \mathrm{~mm}$. Differences of as little as $1 \mathrm{~mm}$ have been implicated in substantial changes in field distribution [36]. In this patient we observed an improvement in mania following a decrease in stimulation intensity and a subjective improvement in OCD symptomatology when we switched to a bipolar stimulation montage (but still employing ventral contacts). It is difficult to separate the effects of TED from those of electrode position and stimulation montage, and the time-response of these symptoms is unknown.
It is possible that patients with a predisposition to psychiatric side effects have a lower intraoperative threshold for stimulation-induced behavioral manifestations. Some of our OCD patients displayed smiles, panic or laughter during intraoperative test stimulation (though this occurred less frequently during subsequent programming [16]). Stimulation-induced smiles occurred during intraoperative test stimulation of 5 of 6 members of our initial OCD DBS cohort [12, 31,37]. These episodes were easily induced (i.e. seen at low voltages) and were usually short in duration. It is unknown whether OCD patients are predisposed to these manifestations or whether these behaviors may also be observed in different cohorts of patients when utilizing the same brain targets.

Though lesion effects might be invoked to explain postoperative side effects, they are unlikely to be implicated in our case. The pulse generators (batteries) were not activated until 30 days following surgery, and the patient was not manic during this time. In most cases lesion effects would be expected to appear immediately. This was not the case for our patient. Her mania appeared immediately following activation of her stimulators. The contribution of the medication changes made is more difficult to assess. Although medication effects cannot be discounted as underpinning at least part of her symptomatic improvement, it should be noted that our patient's mood and OCD symptom changes tracked with our programming adjustments (they occurred temporally within hours of the programming changes). It should also be noted that no medication changes were made after day 0 of symptoms.

DBS programming for psychiatric disease can be complex and difficult to manage. Our patient's case illustrates the potential perils of stimulation-induced side effects as well as the importance of an aggressive management approach. Management may include programming changes, medication changes and even hospitalization. Hardware malfunction should routinely be ruled out as a potential cause. In cases in which a loss of benefit is observed, lead migration should be considered as a possibility and lead localization via neuroimaging may be required.

Potential treatment approaches to stimulation-induced side effects include a reduction in stimulation intensity (current density and voltage) or a shift in point of stimulation to more dorsal contacts on the electrode. Patients should be monitored for impulsivity and suicidal tendencies as psychiatric side effects have the potential to blossom quickly into severe adverse events. 
Patients should not, at this time, be operated on for medication-resistant OCD unless an experienced interdisciplinary team is available to treat urgent management issues. Our practice in programming OCD patients has shifted away from the choice of high initial stimulation strengths and towards more gradual increases in voltage. By doing so, we hope to avoid stimulation-induced manic responses of the sort that were seen in this patient.

\section{Funding}

National Institutes of Health/National Institutes of Mental Health (R21MH064161: Pilot Study of DBS for Treatment-Refractory OCD to W.K.G.); National Parkinson Foundation Center of Excellence grant.

\section{References}

1 Alterman RL, Snyder BJ: Deep brain stimulation for torsion dystonia. Acta Neurochir Suppl 2007;97:191-199.

$\checkmark 2$ Coubes P, Roubertie A, Vayssiere N, Hemm $\mathrm{S}$, Echenne B: Treatment of DYT1-generalised dystonia by stimulation of the internal globus pallidus. Lancet 2000;355:2220-2221.

3 Vidailhet M, Vercueil L, Houeto JL, Krystkowiak P, Benabid AL, Cornu P, Lagrange C, Tezenas du Montcel S, Dormont D, Grand S, Blond S, Detante O, Pillon B, Ardouin C, Agid Y, Destée AP, Pollak P, French Stimulation du Pallidum Interne dans la Dystonie (SPIDY) Study Group: Bilateral deep-brain stimulation of the globus pallidus in primary generalized dystonia. N Engl J Med 2005; 352:498-500.

4 Zorzi G, Marras C, Nardocci N, Franzini A, Chiapparini L, Maccagnano E, Angelini L, Caldiroli D, Broggi G: Stimulation of the globus pallidus internus for childhood-onset dystonia. Mov Disord 2005;20:1194-1200.

5 Kupsch A, Benecke R, Muller J, Trottenberg T, Schneider GH, Poewe W, Eisner W, Wolters A, Muller JU, Deuschl G, Pinsker MO, Skogseid IM, Roeste GK, Vollmer-Haase J, Brentrup A, Krause M, Tronnier V, Schnitzler A, Voges J, Nikkhah G, Vesper J, Naumann M, Volkmann J: Pallidal deep-brain stimulation in primary generalized or segmental dystonia. N Engl J Med 2006;355: 1978-1990.

6 Krauss JK, Loher TJ, Weigel R, Capelle HH, Weber S, JM B: Chronic stimulation of the globus pallidus internus for treatment of non-DYT1 generalized dystonia and choreoathetosis: 2-year follow up. J Neurosurg 2003;98:785-792.

7 Trottenberg T, Volkmann J, Deuschl G, Kuhn AA, Schneider GH, Muller J, Alesch F, Kupsch A: Treatment of severe tardive dystonia with pallidal deep brain stimulation. Neurology 2005;64:344-346.

$\checkmark 8$ Kiss ZH, Doig-Beyaert K, Eliasziw M, Tsui J, Haffenden A, Suchowersky O: The Canadian multicentre study of deep brain stimulation for cervical dystonia. Brain 2007;130:28792886.
-9 Aouizerate B, Martin-Guehl C, Cuny E, Guehl D, Amieva H, Benazzouz A, Fabrigoule C, Bioulac B, Tignol J, Burbaud P: Deep brain stimulation for OCD and major depression. Am J Psychiatry 2005;162:2192.

10 Greenberg BD, Malone DA, Friehs GM, Rezai AR, Kubu CS, Malloy PF, Salloway SP, Okun MS, Goodman WK, Rasmussen SA Three-year outcomes in deep brain stimulation for highly resistant obsessive-compulsive disorder. Neuropsychopharmacology 2006;31:2384-2393.

11 Lozano AM, Mayberg HS, Giacobbe P, Hamani C, Craddock RC, Kennedy SH: Subcallosal cingulate gyrus deep brain stimulation for treatment-resistant depression. Biol Psychiatry 2008;64:461-467.

12 Okun MS, Mann G, Foote KD, Shapira NA, Bowers D, Springer U, Knight W, Martin P Goodman WK: Deep brain stimulation in the internal capsule and nucleus accumbens region: responses observed during active and sham programming. J Neurol Neurosurg Psychiatry 2007;78:310-314.

13 Goodman WK, Foote KD, Greenberg BD, Ricciuti N, Bauer R, Ward H, Shapira NA, Wu SS, Hill CL, Rasmussen SA, Okun MS Deep brain stimulation for intractable obsessive compulsive disorder: pilot study using a blinded, staggered-onset design. Biol Psychiatry 2010;67:535-542.

-14 Nuttin B, Cosyns P, Demeulemeester H, Gybels J, Meyerson B: Electrical stimulation in anterior limbs of internal capsules in patients with obsessive-compulsive disorder. Lancet 1999;354:1526.

15 Aouizerate B, Cuny E, Martin-Guehl C Guehl D, Amieva H, Benazzouz A, Fabrigoule C, Allard M, Rougier A, Bioulac B, Tignol J, Burbaud P: Deep brain stimulation of the ventral caudate nucleus in the treatment of obsessive-compulsive disorder and major depression: case report. J Neurosurg 2004;101:682-686.

16 Springer US, Bowers D, Goodman WK, Shapira NA, Foote KD, Okun MS: Long-term habituation of the smile response with deep brain stimulation. Neurocase 2006;12:191196.
17 Kulisevsky J, Berthier ML, Gironell A, Pascual-Sedano B, Molet J, Pares P: Mania following deep brain stimulation for Parkinson's disease. Neurology 2002;59:1421-1424.

$>18$ Raucher-Chene D, Charrel CL, de Maindreville $\mathrm{AD}$, Limosin F: Manic episode with psychotic symptoms in a patient with Parkinson's disease treated by subthalamic nucleus stimulation: improvement on switching the target. J Neurol Sci 2008;273:116-117.

19 Miyawaki E, Perlmutter JS, Troster AI, Videen TO, Koller WC: The behavioral complications of pallidal stimulation: a case report. Brain Cogn 2000;42:417-434.

20 Greenberg BD, Gabriels LA, Malone DA Jr, Rezai AR, Friehs GM, Okun MS, Shapira NA, Foote KD, Cosyns PR, Kubu CS, Malloy PF, Salloway SP, Giftakis JE, Rise MT, Machado AG, Baker KB, Stypulkowski PH, Goodman WK, Rasmussen SA, Nuttin BJ: Deep brain stimulation of the ventral internal capsule/ventral striatum for obsessivecompulsive disorder: worldwide experience. Mol Psychiatry 2010;15:64-79.

21 Mandat TS, Hurwitz T, Honey CR: Hypomania as an adverse effect of subthalamic nucleus stimulation: report of two cases. Acta Neurochir (Wien) 2006;148:895-897; discussion 898.

$>22$ Romito LM, Raja M, Daniele A, Contarino MF, Bentivoglio AR, Barbier A, Scerrati M, Albanese A: Transient mania with hypersexuality after surgery for high-frequency stimulation of the subthalamic nucleus in Parkinson's disease. Mov Disord 2002;17: 1371-1374.

23 Bejjani BP, Damier P, Arnulf I, Thivard L, Bonnet AM, Dormont D, Cornu P, Pidoux B, Samson Y, Agid Y: Transient acute depression induced by high-frequency deep-brain stimulation. N Engl J Med 1999;340:14761480.

24 Coenen VA, Honey CR, Hurwitz T, Rahman AA, McMaster J, Burgel U, Madler B: Medial forebrain bundle stimulation as a pathophysiological mechanism for hypomania in subthalamic nucleus deep brain stimulation for Parkinson's disease. Neurosurgery 2009; 64:1106-1114; discussion 1114-1105. 
-25 Benabid AL, Chabardes S, Mitrofanis J, Pollak P: Deep brain stimulation of the subthalamic nucleus for the treatment of Parkinson's disease. Lancet Neurol 2009;8:67-81.

-26 Nakano K: Neural circuits and topographic organization of the basal ganglia and related regions. Brain Dev 2000;22(suppl 1):S5-S16.

27 Temel Y, Kessels A, Tan S, Topdag A, Boon P, Visser-Vandewalle V: Behavioural changes after bilateral subthalamic stimulation in advanced Parkinson disease: a systematic review. Parkinsonism Relat Disord 2006;12: 265-272.

-28 Van den Heuvel OA, Veltman DJ, Groenewegen HJ, Cath DC, van Balkom AJ, van Hartskamp J, Barkhof F, van Dyck R: Frontalstriatal dysfunction during planning in obsessive-compulsive disorder. Arch Gen Psychiatry 2005;62:301-309.

29 Baldo BA, Kelley AE: Discrete neurochemical coding of distinguishable motivational processes: insights from nucleus accumbens control of feeding. Psychopharmacology (Berl) 2007;191:439-459.
30 Deadwyler SA, Hayashizaki S, Cheer J, Hampson RE: Reward, memory and substance abuse: functional neuronal circuits in the nucleus accumbens. Neurosci Biobehav Rev 2004;27:703-711.

31 Haq IU, Foote KD, Goodman WG, Wu SS, Sudhyadhom A, Ricciutti N, Siddiqui MS, Bowers D, Jacobson CE, Ward H, Okun MS Smile and laughter induction and intraoperative predictors of response to deep brain stimulation for obsessive compulsive disorder. Neuroimage 2010, Epub ahead of print.

32 Bermpohl F, Kahnt T, Dalanay U, Hagele C, Sajonz B, Wegner T, Stoy M, Adli M, Kruger S, Wrase J, Strohle A, Bauer M, Heinz A: Altered representation of expected value in the orbitofrontal cortex in mania. Hum Brain Mapp 2009, Epub ahead of print

>33 McCracken CB, Grace AA: High-frequency deep brain stimulation of the nucleus accumbens region suppresses neuronal activity and selectively modulates afferent drive in rat orbitofrontal cortex in vivo. J Neurosci 2007;27:12601-12610
34 Moreau C, Defebvre L, Destee A, Bleuse S, Clement F, Blatt JL, Krystkowiak P, Devos D: STN-DBS frequency effects on freezing of gait in advanced Parkinson disease. Neurology 2008;71:80-84.

35 McIntyre CC, Butson CR, Maks CB, Noecker AM: Optimizing deep brain stimulation parameter selection with detailed models of the electrode-tissue interface. Conf Proc IEEE Eng Med Biol Soc 2006;1:893-895.

>36 McIntyre CC, Savasta M, Kerkerian-Le Goff L, Vitek JL: Uncovering the mechanism(s) of action of deep brain stimulation: activation, inhibition, or both. Clin Neurophysiol 2004; 115:1239-1248.

37 Okun MS, Bowers D, Springer U, Shapira NA, Malone D, Rezai AR, Nuttin B, Heilman KM, Morecraft RJ, Rasmussen SA, Greenberg BD, Foote KD, Goodman WK: What's in a 'smile?' Intra-operative observations of contralateral smiles induced by deep brain stimulation. Neurocase 2004;10:271-279. 